\title{
Where Are We with Deep Brain Stimulation? A Review of Scientific Publications and Ongoing Research
}

\author{
Irene E. Harmsen ${ }^{a}$ Filipe Wolff Fernandes ${ }^{b}$ Joachim K. Krauss ${ }^{b}$ Andres M. Lozano ${ }^{a}$ \\ aDivision of Neurosurgery, Department of Surgery, Toronto Western Hospital, University of Toronto, Toronto, ON, Canada; \\ ${ }^{b}$ Department of Neurosurgery, Hannover Medical School, Hannover, Germany
}

\section{Keywords}

Deep brain stimulation · Trends · Movement disorders .

Psychiatric disorders $\cdot$ Cognitive disorders

\begin{abstract}
Background: Deep brain stimulation (DBS) is a neuromodulatory technique that delivers adjustable electrical stimuli to brain targets to relieve symptoms associated with dysregulated neural circuitry. Over the last several decades, DBS has been applied to a number of conditions, including motor, pain, mood, and cognitive disorders. An assessment of the body of work in this field is warranted to determine where we have been, define the current state of the field, and chart a path toward the future. Objective: The aim of the study was to assess the state of DBS-related research by analyzing the DBS literature as well as active studies sponsored by the National Institutes of Health (NIH) or German Research Foundation (Deutsche Forschungsgemeinschaft [DFG]). Methods: Peer-reviewed DBS publications were extracted from PubMed. Active NIH-funded DBS projects were extracted from the RePORT database and active DFG projects from the German Research Foundation database. Records were analyzed using custom-developed algorithms to generate a de-
\end{abstract}

tailed overview of past and present DBS-related research. Specifically, records were categorized by publication year, journal, language, country of origin, contributing authors, disorder, brain target, study design, and topic. Expected project duration and costs were also provided for active studies. Results: In total, 8,974 publications, 172 active $\mathrm{NIH}$-funded projects, and 34 active DFG projects were identified. Records spanned 52 different disorders across 31 distinct brain targets and showed a recent shift toward studies examining conditions other than movement disorders. Most published works involved human research ( $80.6 \%$ of published studies), of which $10.2 \%$ were identified as clinical trials. Increasingly, studies focused on imaging or electrophysiological changes associated with DBS $(69.8 \% \mathrm{NIH}$-active and $70.6 \%$ DFG-active vs. $25.8 \%$ published) or developing new stimulation techniques and adaptive technologies $(37.8 \% \mathrm{NIH}$-active and $17.6 \%$ DFG-active vs. $6.5 \%$ published). Conclusions: This overview of past and present DBS-related studies provides insight into the status of DBS research and what we can anticipate in the future concerning new indications, improved/ novel target selection and stimulation paradigms, closedloop technology, and a better understanding of the mechanisms of action of DBS.

(c) 2022 The Author(s)

Published by S. Karger AG, Basel karger@karger.com www.karger.com/sfn

Karger $\stackrel{\text { ' }}{5}$

BOPEN ACCESS
(C) 2022 The Author(s)

Published by S. Karger AG, Basel

This is an Open Access article licensed under the Creative Common Attribution-NonCommercial-4.0 International License (CC BY-NC) (http://www.karger.com/Services/OpenAccessLicense), applicable to the online version of the article only. Usage and distribution for commercial purposes requires written permission.
Correspondence to:

Andres M. Lozano, lozano@ uhnresearch.ca 


\section{Introduction}

Deep brain stimulation (DBS) is a specific form of neuromodulation which uses electrodes implanted in the brain to electrically stimulate specific structures and modulate dysregulated neural circuitry [1]. DBS represents an important breakthrough in translational neuroscience for several reasons. DBS allows the probing of brain circuits during implantation and stimulation mapping. In addition, DBS has a profile of relatively safe therapeutic efficacy and has important properties, including its reversible and adjustable nature. It has become an established therapeutic approach for patients with movement disorders, such as Parkinson's disease, essential tremor, and dystonia, and is increasingly being examined for its use in treating other neurological and psychiatric disorders [2-4].

Despite the many advancements since its discovery, the field of DBS has the potential for much more growth. DBS currently involves the continuous stimulation of the target structure, an approach that cannot adapt to patients' changing symptoms or functional status in real-time. The chronic delivery of stimulation pulses is associated with stimulation-induced adverse effects, such as speech impairments and an increased risk of falls [5-7]. Continuous stimulation also increases battery consumption, which requires repeat surgeries that are not without complications. Moreover, DBS systems need to be individually programmed by trained experts to achieve symptom relief. This process is often cumbersome, based on trial and error, and requires frequent patient visits to tertiary care centers. It is also not feasible to manually test all permutations of stimulation frequency, amplitude, and pulse width, which results in unoptimized patient settings. Further, many symptoms such as epilepsy, depression, and dystonia show a long latency, sometimes weeks or months between stimulation and clinical response, and improve in a delayed and progressive manner. These delayed and cumulative effects add complexity to the selection of optimal stimulation parameters. Developments in DBS techniques and technologies are needed for optimizing the spatially and temporally targeted delivery of stimulation [8]. The analysis of past and current research trends in DBS practice and characterization of active studies can provide insights into the challenges and opportunities for advancing the field.

\section{Methods and Materials}

A search for all peer-reviewed articles pertaining to DBS was conducted using PubMed (https://pubmed.ncbi.nlm.nih.gov/) on March 22, 2021. Given the breadth of research in the field, only ar- ticle titles and abstracts were searched using the term "deep brain stimulation." After removing duplicates, publications were screened for original articles, which resulted in the exclusion of meta-analyses, reviews, book chapters, commentaries, editorials, reader comments, author responses, and retractions (Fig. 1a). Records were then assessed for eligibility, and non-DBS-related articles were excluded. Citation counts for the included publications were extracted from the Web of Science (https://login.webofknowledge.com) on June 25, 2021. A separate search was conducted to evaluate active National Institutes of Health (NIH)-funded DBS projects in the USA. This took place on June 16, 2021, using the RePORT database (https:// report.nih.gov/) and the search term "deep brain stimulation." To gain a more global perspective on DBS research activity, active DBS studies in Germany were also evaluated using the GEPRIS database (https://gepris.dfg.de/gepris) of the German Research Foundation (Deutsche Forschungsgemeinschaft [DFG]). This search was conducted on September 9, 2021, using the search terms "deep brain stimulation," "tiefe hirnstimulation," and "tiefenhirnstimulation." Only active NIH and DFG projects were selected. Duplicates were then removed, and non-DBS-related projects excluded.

Eligible publications and active projects were separately analyzed using custom-developed scripts in MATLAB (MathWorks, Natick, MA, USA). Publication year, journal, language, and authors were recorded as posted in study records. Author contributions did not account for the order of appearance (i.e., first, middle, and last author). The country of origin was determined according to the country of the responsible party (i.e., last author, lead center in multicenter studies). For features not posted in study records or grant entries (e.g., clinical disorder, brain target, study design, and topic), keyword searching algorithms were used on extracted titles then abstracts. For reporting purposes, clinical disorders treated with DBS were broadly categorized as either "movement disorder," "psychiatric disorder," "cognitive disorder," "epilepsy," "pain," or "other." The brain target for electrode insertion was also grouped into more general categories where appropriate. Where applicable, "rate of change" metrics were calculated to examine how rapidly records of different indications, targets, or topics were being published.

\section{Results}

Our search of the PubMed database for all reports on DBS generated an initial list of 12,024 publications. Following the removal of duplicates and screening for pertinence to DBS, a total of 8,974 original articles were identified (Fig. 1a).

\section{Studies by Publication Year}

Results span 4 decades of DBS research, from 1979 to 2021. Figure 2 shows the yearly growth in the number of publications up to 2020 and highlights significant DBS milestones. While it has been outlined previously that chronic DBS was used since the early 1950s [9], the earliest paper on DBS using our search criteria was by Stock and colleagues [10] on the influence of chronic DBS on tissue excitability and morphology. The absence of stim- 


\section{Peer-reviewed DBS publications}

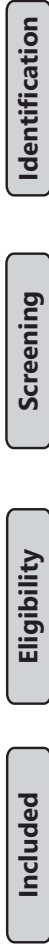

a

Active German-funded DBS projects
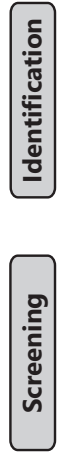

Records identified with

GEPRIS database search $(n=65)$

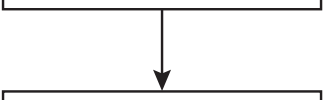

Records after duplicates removed $(n=65)$
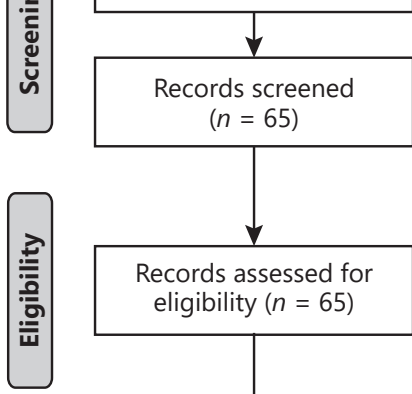

Records assessed for eligibility $(n=65)$

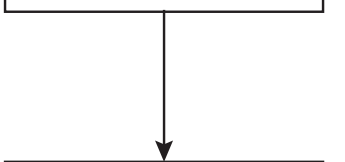

Exclusion of non-DBS-related records $(n=14)$

records ( $n=3,017$ ):

Meta-analyses and

(systematic) reviews

$(n=2,849)$

Commentaries and

editorials ( $n=25$ )

Reader comments

$(n=61)$

Author responses

$n=77)$

- Retractions $(n=5)$

Records included fo

analyses $(n=8,974)$

Records included for analyses $(n=34)$
Exclusion of non-DBS-related records $(n=31)$

\section{Active NIH-funded DBS projects}

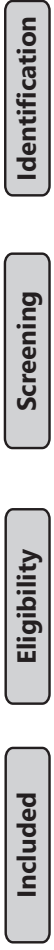

Records identified with

RePORT database search $(n=356)$

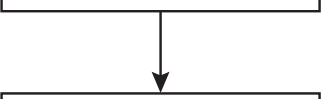

Records after duplicates

removed $(n=329)$

Records screened $(n=329)$

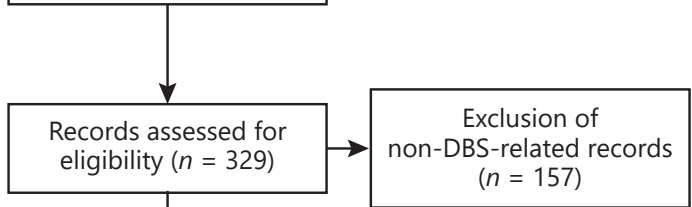

Records included for analyses $(n=172)$

1

(For legend see next page.)

Harmsen/Wolff Fernandes/Krauss/ Lozano 


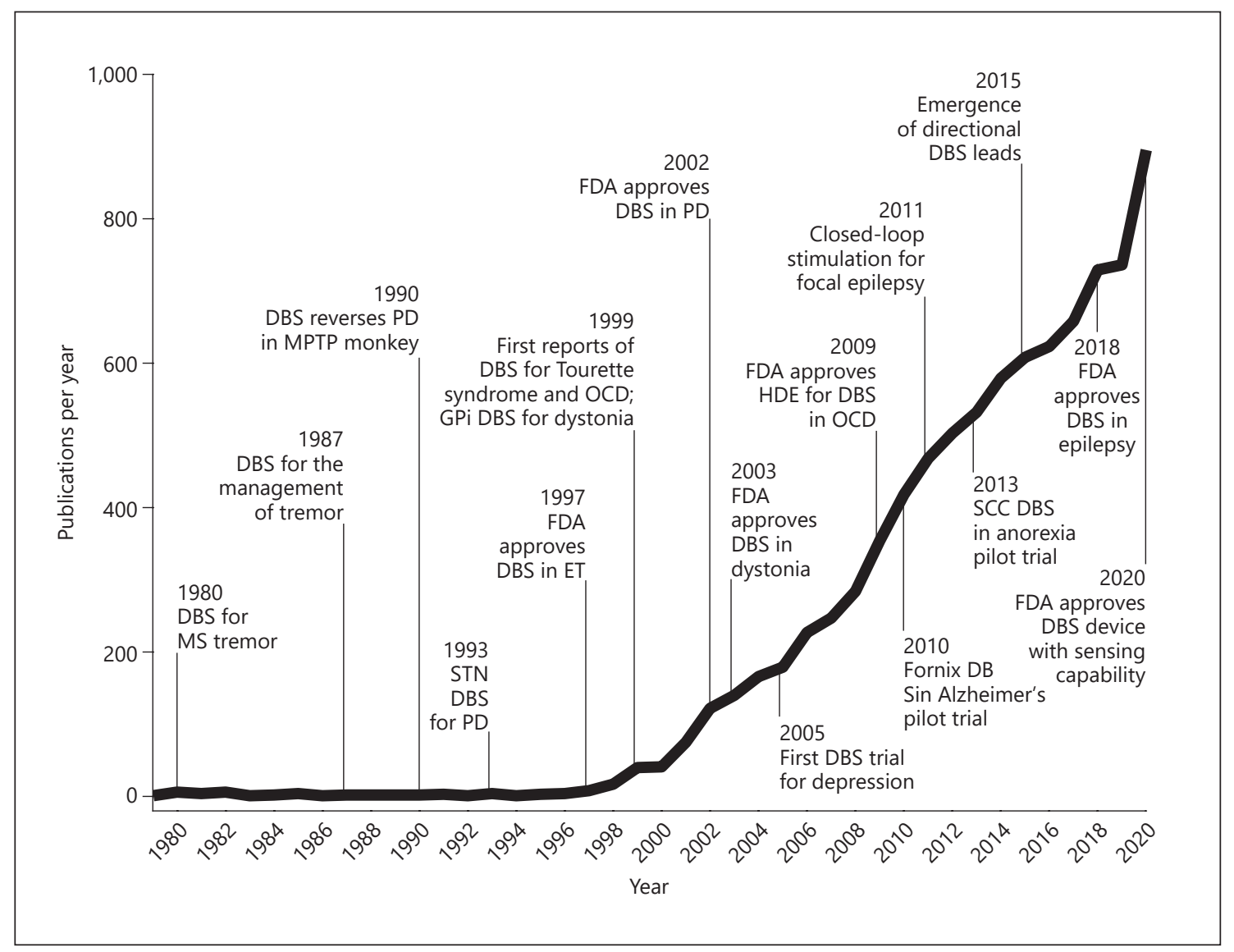

Fig. 2. Timeline and yearly growth in the number of DBS publications from 1979 to 2020 . Around 8,696 studies were published between 1979 and 2020 with major DBS milestones highlighted. Adapted with permission from Lozano and Lipsman [2].

ulation-induced changes in neural tissue paved the way for clinical use of chronic DBS implants in tremor associated with multiple sclerosis, Parkinson's disease, essential tremor, and pain [11-14]. Following the success of DBS for Parkinson's disease and tremor in the 1980s-1990s, it was also applied to dystonia since the mid-1990s [15-17] and to psychiatric disorders, namely Tourette syndrome and obsessive-compulsive disorder (OCD), starting in $1999[18,19]$. DBS was trialed in patients with treatmentresistant depression beginning in 2005, Alzheimer's disease in 2010, and anorexia nervosa in 2013 [20-22]. In addition to exploring novel indications, many advancements in DBS technology have been made [8]. In 2011, a

Fig. 1. PRISMA flow diagram. Overview of the number of records that were identified, screened, eligible, and included in the analysis for DBS-related publications (PubMed database) (a), active NIHfunded projects (RePORT database) (b), and active German-sponsored projects (GEPRIS database) $(\mathbf{c})$.

Where Are We with DBS? closed-loop stimulation system, NeuroPace RNS ${ }^{\circledR}$, was introduced to treat focal epilepsy, followed by the approval of DBS devices with sensing capabilities (e.g., Medtronic Percept $\left.{ }^{\mathrm{TM}}\right)$ a decade later. Additionally, 2015 saw the emergence of directional leads (Boston Scientific Verci$\mathrm{se}^{\mathrm{TM}}$ ), which further contributed to expanding the stimulation parameter space.

\section{Studies by Journal, Language, Country of Origin, and}

\section{Author}

The approximately 9,000 identified DBS studies were published in 982 different journals in 18 languages by researchers from 91 countries. The top 20 journals with the most publications are listed in Table 1, comprising $42.1 \%$ of studies. Most studies (97.4\%) were published in English with the remainder written in French (57 studies, 0.6\%), German (48 studies, 0.5\%), Japanese (37 studies, $0.4 \%$ ), Chinese (21 studies, $0.2 \%$ ), Spanish (21 studies, $0.2 \%$ ), and other (52 studies, $0.6 \%$ ). By the country of 
Table 1. Top 20 journals publishing DBS research
Fig. 3. Country of origin of published DBS studies. Out of 91 countries that have published on DBS, the top 5 countries that account for the highest percentage of publications include the USA (38.3\%), Germany (14.9\%), the UK (9.5\%), France $(8.1 \%)$, and Canada $(7.5 \%)$.

\begin{tabular}{|c|c|c|c|}
\hline Journal & Impact factor & Studies, $n$ & Total studies, \% \\
\hline Mov Disord & 8.679 & 431 & 4.8 \\
\hline Stereotact Funct Neurosurg & 1.972 & 385 & 4.3 \\
\hline J Neurosurg & 4.130 & 353 & 3.9 \\
\hline Parkinsonism Relat Disord & 3.926 & 306 & 3.4 \\
\hline Brain Stimul & 6.919 & 212 & 2.4 \\
\hline Neuromodulation & 4.029 & 204 & 2.3 \\
\hline Neurosurgery & 4.605 & 200 & 2.2 \\
\hline J Neurol Neurosurg Psychiatry & 8.234 & 176 & 2.0 \\
\hline Annu Int Conf IEEE Eng Med Biol Soc & 0.910 & 174 & 1.9 \\
\hline World Neurosurg & 1.723 & 171 & 1.9 \\
\hline Neurology & 8.055 & 166 & 1.8 \\
\hline Acta Neurochir (Wien) & 2.122 & 150 & 1.7 \\
\hline Brain & 11.337 & 135 & 1.5 \\
\hline PLoS One & 2.740 & 128 & 1.4 \\
\hline J Neurol & 3.783 & 111 & 1.2 \\
\hline Clin Neurophysiol & 3.614 & 99 & 1.1 \\
\hline Neuroimage & 5.902 & 96 & 1.1 \\
\hline J Clin Neurosci & 1.593 & 95 & 1.1 \\
\hline J Neural Eng & 4.141 & 95 & 1.1 \\
\hline Exp Neurol & 4.562 & 93 & 1.0 \\
\hline Total & & 3,780 & 42.1 \\
\hline
\end{tabular}

Around 962 Journals, containing 5,194 (57.9\%) studies, are not listed in the above table. Zero studies $(0.0 \%)$ were missing data on the journal it was published in.

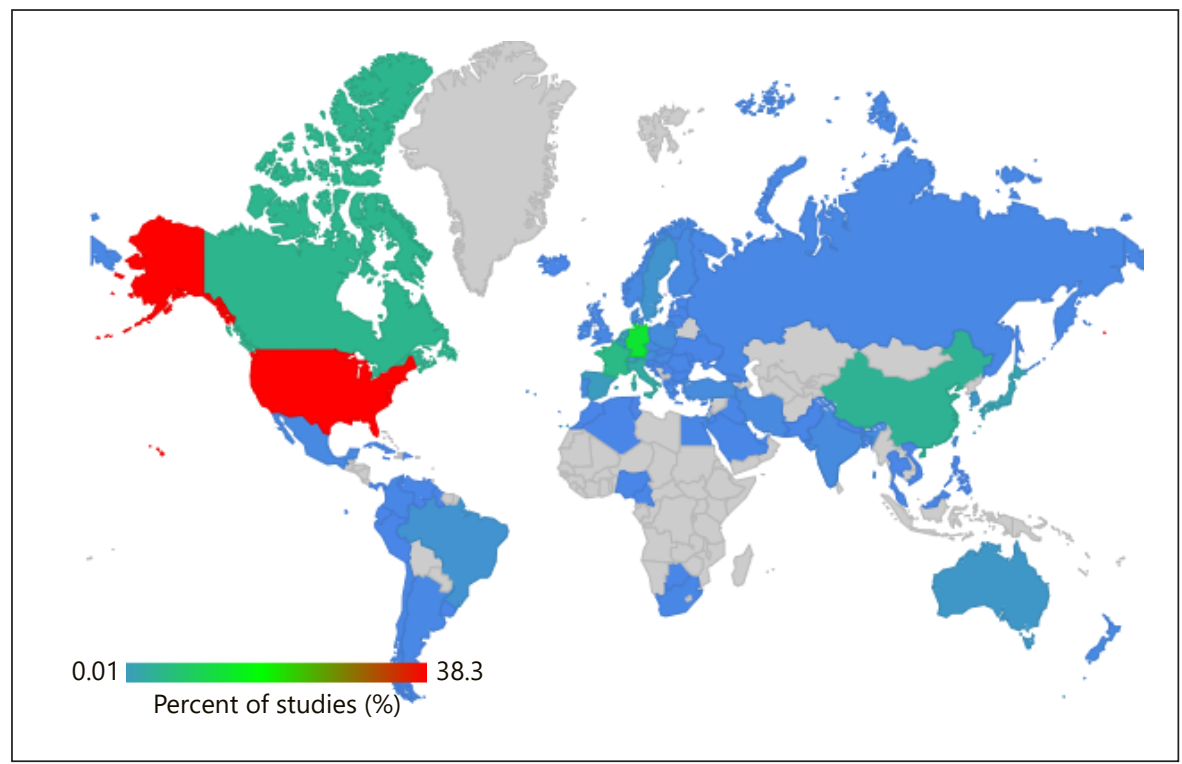

study origin, the top 5 countries that accounted for the highest percentage of reports include the USA (38.3\%), Germany (14.9\%), the UK (9.5\%), France (8.1\%), and Canada (7.5\%) (Fig. 3). The top 5 publishing authors are Lozano AM (3.0\%), Okun MS (2.6\%), Aziz TZ (2.0\%), Foote KD (1.9\%), and Limousin P (1.5\%).

\section{Studies by Clinical Disorder and the Brain Target}

DBS has been applied to over 50 different conditions (Table 2). Over two-thirds of DBS studies pertained to movement disorders (71.6\%), followed by psychiatric disorders (15.3\%), epilepsy (5.2\%), cognitive disorders (3.4\%), pain (3.1\%), and other (1.4\%) (Fig. 4a left). Over 4 decades, 
Table 2. DBS has been applied to over 50 clinical disorders

\begin{tabular}{|c|c|c|c|}
\hline Disorder type & Clinical disorder & Studies, $n$ & Studies, \% \\
\hline \multirow[t]{23}{*}{ Movement disorders } & Parkinson disease & 3,909 & 45.2 \\
\hline & Dystonia & 854 & 9.9 \\
\hline & Essential tremor & 445 & 5.1 \\
\hline & Tourette syndrome (tremor) & 181 & 2.1 \\
\hline & Myoclonus & 45 & 0.5 \\
\hline & Multiple sclerosis & 43 & 0.5 \\
\hline & Camptocormia & 34 & 0.4 \\
\hline & Huntington disease & 34 & 0.4 \\
\hline & Cerebral palsy & 25 & 0.3 \\
\hline & Meige syndrome & 24 & 0.3 \\
\hline & Chorea-acanthocytosis & 19 & 0.2 \\
\hline & Pantothenate kinase-associated neurodegeneration & 17 & 0.2 \\
\hline & Multiple system atrophy & 16 & 0.2 \\
\hline & Progressive supranuclear palsy & 13 & 0.2 \\
\hline & Restless-leg syndrome & 13 & 0.2 \\
\hline & Hemichorea and hemiballism & 11 & 0.1 \\
\hline & Cerebellar ataxia & 8 & 0.1 \\
\hline & Dysphonia & 8 & 0.1 \\
\hline & Blepharospasm & 6 & 0.1 \\
\hline & Ataxia-telangiectasia & 2 & 0.0 \\
\hline & Primary progressive freezing of gait & 2 & 0.0 \\
\hline & Tremor, unspecified & 264 & 3.0 \\
\hline & Not specified & 224 & 2.6 \\
\hline \multirow[t]{12}{*}{ Psychiatric disorders } & Depression and bipolar disorder & 402 & 4.6 \\
\hline & OCD & 284 & 3.3 \\
\hline & Substance use disorder/addiction & 101 & 1.2 \\
\hline & Anxiety & 59 & 0.7 \\
\hline & Anorexia nervosa & 36 & 0.4 \\
\hline & Obesity & 33 & 0.4 \\
\hline & Schizophrenia & 28 & 0.3 \\
\hline & Aggression and explosive disorder & 27 & 0.3 \\
\hline & Autism spectrum disorder & 15 & 0.2 \\
\hline & Post-traumatic stress disorder & 15 & 0.2 \\
\hline & Body dysmorphic disorder & 1 & 0.0 \\
\hline & Not specified & 324 & 3.7 \\
\hline Epilepsy & Epilepsy/seizure & 449 & 5.2 \\
\hline \multirow[t]{4}{*}{ Cognitive disorders } & Dementia/memory & 216 & 2.5 \\
\hline & Decreased level of consciousness/arousal & 75 & 0.9 \\
\hline & Rett syndrome & 3 & 0.0 \\
\hline & Traumatic brain injury & 3 & 0.0 \\
\hline \multirow[t]{5}{*}{ Pain } & Headache/cephalgia/migraine & 82 & 0.9 \\
\hline & Neuropathic & 54 & 0.6 \\
\hline & Central poststroke pain & 17 & 0.2 \\
\hline & Trigeminal neuropathy & 8 & 0.1 \\
\hline & Not specified & 105 & 1.2 \\
\hline \multirow[t]{8}{*}{ Other } & Stroke & 41 & 0.5 \\
\hline & Urinary dysfunction & 24 & 0.3 \\
\hline & Tinnitus & 21 & 0.2 \\
\hline & Stuttering & 12 & 0.1 \\
\hline & Spinal cord injury & 11 & 0.1 \\
\hline & Hyperhidrosis & 5 & 0.1 \\
\hline & Hypertension & 3 & 0.0 \\
\hline & Breathlessness in COPD & 1 & 0.0 \\
\hline Total & & 8,652 & 100.0 \\
\hline
\end{tabular}

Around 1,304 studies (14.5\%) were missing data on clinical indication, and 1,097 studies (12.2\%) provided more than one clinical indication. 
the number of publications per year has increased exponentially for movement disorders from $0.1(1981-1990)$ to 8.6 (1991-2000) to 147.0 (2001-2010) to 365.9 (2011-2020) (Fig. 4a right; online suppl. Table 1; for all online suppl. material, see www.karger.com/doi/10.1159/000521372). In contrast, growth has been slower for psychiatric disorders, epilepsy, cognitive disorders, and pain. Some of the more novel indications described, each with no more than fifteen publications, include primary progressive freezing of gait [23], autism spectrum disorder [24], body dysmorphic disorder [25], traumatic brain injury [26], postherpetic trigeminal neuropathy [27], and breathlessness in COPD [28].

From the 8,974 studies published since 1979, 31 distinct brain regions were targeted (Table 3; Fig. $4 \mathrm{~b}$ left). Motor areas accounted for $78.3 \%$ of targets and included subcortical components of the cortico-basal ganglia-thalamocortical motor circuit and cerebellum. Studies on the subthalamic nucleus (STN) dominate the literature, accounting for $39.1 \%$ of all targets used. The globus pallidus internus (GPi) and ventral intermediate nucleus of thalamus are more or less tied for the second- and third-most commonly used targets, representing $16.3 \%$ and $16.0 \%$ of all targets, respectively. Relatively newer motor targets include the dentatorubrothalamic tract and prelemniscal radiation, both of which are used for refractory tremor $[29,30]$. Affective limbic structures were the next most frequently engaged group of targets, making up $14.9 \%$ of all targets used. Within this group, the top 3 regions include the bed nucleus of stria terminalis, nucleus accumbens, and anterior limb of the internal capsule, all of which are primarily used for OCD but also for depression and substance use disorders. A less commonly used target that shows promise for treating OCD and depression is the inferior thalamic peduncle [31, 32]. Structures that belong to both the motor and limbic circuits, such as the caudate and centromedian/parafascicular complex, collectively comprise $1.4 \%$ of targets and are used for OCD, Tourette syndrome, and pain [33-35]. Memory circuit structures are the least targeted at $1.0 \%$ of all targets and include the fornix and nucleus basalis to treat dementias. Although the hippocampus has an integral role in learning and memory, hippocampal stimulation is more commonly used for epilepsy than treating cognitive disorders. Given that brain targets are related to clinical indication for DBS, we see the same trend of an exponential increase in motor targets as we did for movement disorders treated with lesioning over 40 years. The number of publications per year for DBS motor targets has increased from 0.2 (1981-1990) to $8.4(1991-2000)$ to $130.8(2001-2010)$ to $305.1(2011-2020)$, whereas growth has been slower for limbic, motor/limbic, and memory targets (Fig. $4 \mathrm{~b}$ right; online suppl. Table 2 ).
Table 3. Over 30 brain regions have been targeted with DBS

\begin{tabular}{|c|c|c|c|}
\hline Circuit & Brain region & Studies, $n$ & Studies, \% \\
\hline \multirow[t]{13}{*}{ Motor } & STN & 2,913 & 39.1 \\
\hline & GPi & 1,216 & 16.3 \\
\hline & VIM & 1,188 & 16.0 \\
\hline & $\mathrm{SNr}$ & 105 & 1.4 \\
\hline & PPN & 100 & 1.3 \\
\hline & Cerebellum & 57 & 0.8 \\
\hline & $c Z i$ & 53 & 0.7 \\
\hline & $\mathrm{GPe}$ & 42 & 0.6 \\
\hline & VO & 40 & 0.5 \\
\hline & Putamen & 38 & 0.5 \\
\hline & PSA & 34 & 0.5 \\
\hline & DRT & 30 & 0.4 \\
\hline & RaPRL & 10 & 0.1 \\
\hline \multirow[t]{10}{*}{ Limbic } & BNST & 320 & 4.3 \\
\hline & NAc & 219 & 2.9 \\
\hline & ALIC & 150 & 2.0 \\
\hline & PFC & 116 & 1.6 \\
\hline & SCG & 94 & 1.3 \\
\hline & VC/VS & 72 & 1.0 \\
\hline & Amygdala & 58 & 0.8 \\
\hline & MFB & 53 & 0.7 \\
\hline & Habenula & 24 & 0.3 \\
\hline & ITP & 4 & 0.1 \\
\hline \multirow[t]{2}{*}{ Motor/Limbic } & Caudate & 60 & 0.8 \\
\hline & CM-Pf complex & 44 & 0.6 \\
\hline \multirow[t]{2}{*}{ Memory } & Fornix & 40 & 0.5 \\
\hline & NBM & 33 & 0.4 \\
\hline \multirow[t]{4}{*}{ Other } & Hippocampus & 122 & 1.6 \\
\hline & Hypothalamus & 78 & 1.0 \\
\hline & PVG/PAG & 76 & 1.0 \\
\hline & ANT & 56 & 0.8 \\
\hline Total & & 7,445 & 100.0 \\
\hline
\end{tabular}

Around 3,179 studies (35.4\%) were missing data on the brain target, and 1,650 studies (18.4\%) provided more than one brain target. VIM, ventral intermediate nucleus of thalamus; DRT, dentatorubrothalamic tract; RaPRL, prelemniscal radiation; BNST, bed nucleus of stria terminalis; NAc, nucleus accumbens; ALIC, anterior limb of the internal capsule; ITP, inferior thalamic peduncle; CM-Pf, centromedian/parafascicular; SNr, substantia nigra; PPN, pedunculopontine nucleus; cZi, caudal zona incerta; GPe, globus pallidus externus; VO, ventro-oralis nucleus of the thalamus; PSA, posterior subthalamic area; PFC, prefrontal cortex; SCG, subgenual anterior cingulate/subcallosal area; VC/VS, ventral capsule/ventral striatum; MFB, medial forebrain bundle; NBM, nucleus basalis of Meynert; PVG/PAG, periventricular/ periaqueductal gray; ANT, anterior nucleus of the thalamus.

\section{Studies by the Design and Primary Topic}

To survey the main content and design of identified DBS reports, studies were first characterized as involving human $(80.6 \%)$ or nonhuman $(19.4 \%)$ research. Of the nonhuman animal studies, $50.4 \%$ used rodent models, $10.3 \%$ used nonhuman primates, and $2.8 \%$ used other animals (swine and 


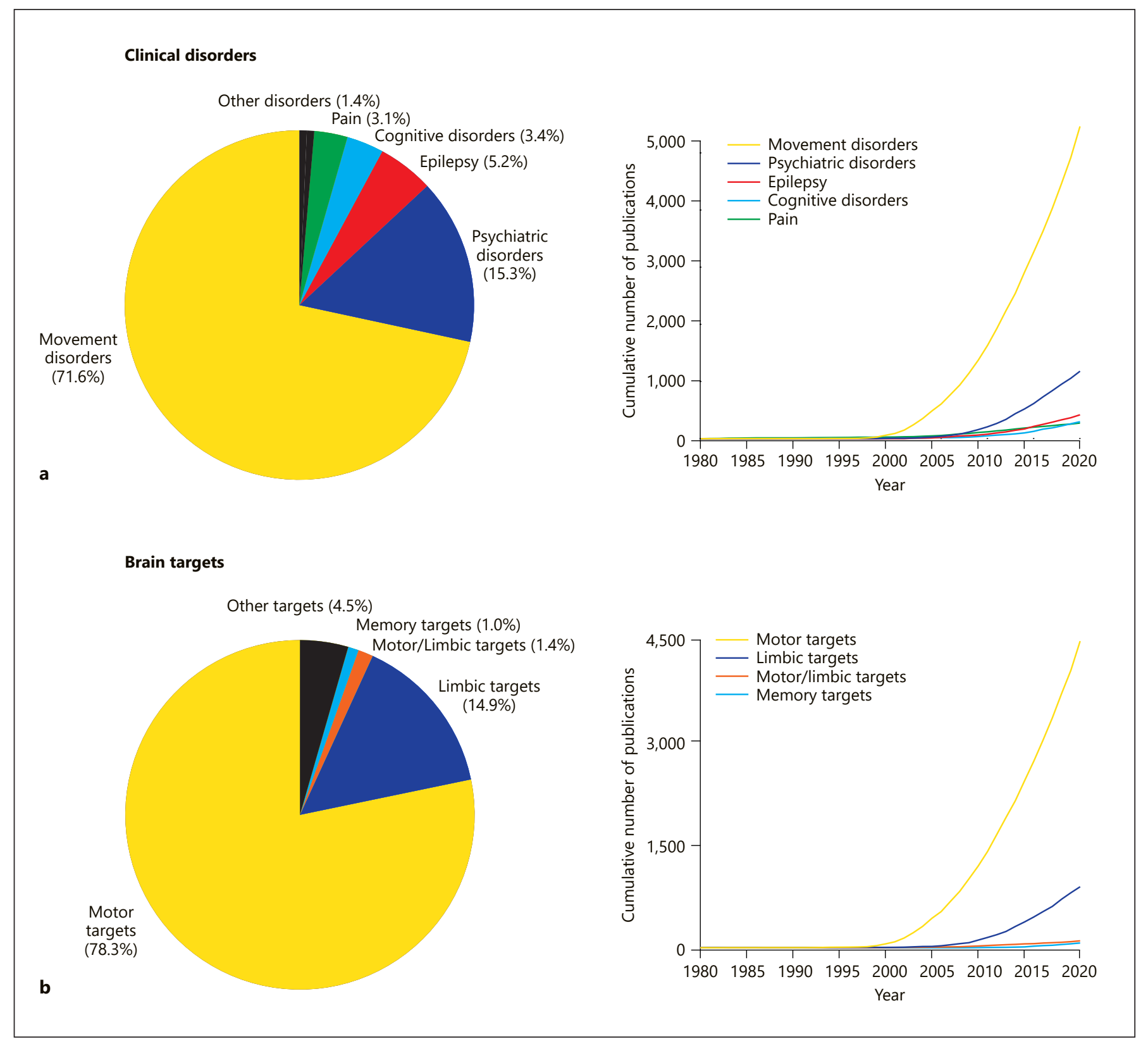

Fig. 4. Clinical disorders and brain targets of published DBS studies. a Pie chart (left) represents the percentage of publications categorized by major clinical disorder. Line plots (right) of the major clinical disorder categories show cumulative growth in the number of publications from 1979 to 2020. b Same as (a) but for major brain target categories.

sheep). Another $26.2 \%$ were in silico, $6.0 \%$ were in vitro, and $4.2 \%$ were phantom studies. Of the human clinical research, $10.2 \%$ of publications were identified as clinical trials.

With regards to content, $25.8 \%$ of total publications included DBS-related neuroimaging or electrophysiological recordings (e.g., functional magnetic resonance imaging, positron emission tomography, local field potentials, elec- trocorticography, electromyography, electroencephalography, and magnetoencephalography). The use of a neuroimaging/electrophysiological component in studies has exponentially increased from 0.1 publication per year (1981-1990) to $1.2(1991-2000)$ to 48.3 (2001-2010) to 175.5 (2011-2020). Other studies (13.6\% of total publications) focused on reporting adverse outcomes of DBS, 


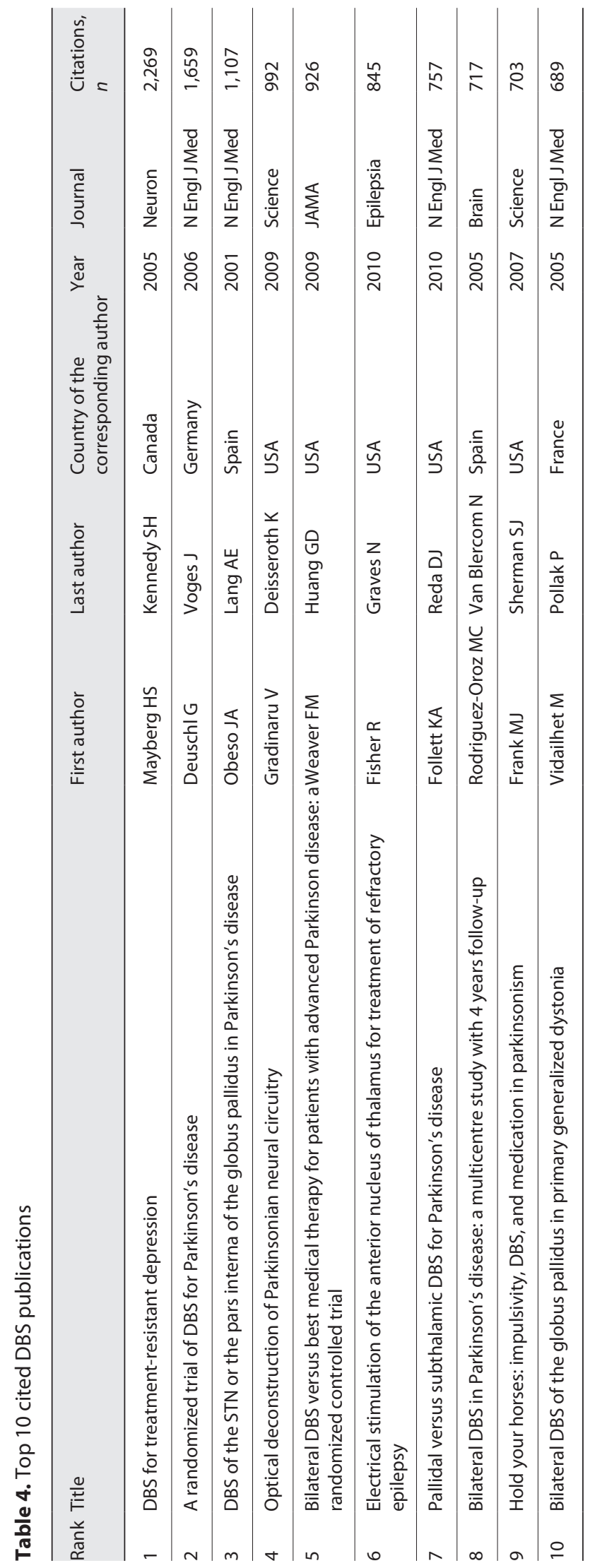

namely, stimulation-induced effects (dysarthria and cognitive decline), infection, and surgical complications (intracranial hemorrhage and pneumocephalus). Less common adverse outcomes included hypomania-like syndrome induced by DBS [36], intraparenchymal cyst [37], idiopathic delayed-onset edema [38], and malignant neuroleptic syndrome due to deep brain stimulator withdrawal [39].

The development of new stimulation technologies and techniques was another theme among publications. This includes increasing the DBS parameter space (3.9\% of total publications) and developing closed-loop systems (2.6\% of total publications) to optimize therapeutic outcomes and reduce stimulation-induced adverse effects. Similarly, surgical and device advancements that should optimize the patient experience include asleep procedures using MRI guidance ( $0.4 \%$ of total publications), frameless stereotaxy ( $0.5 \%$ of total publications), and rechargeable IPGs ( $0.4 \%$ of total publications).

\section{Most Cited Publications}

To determine important contributions to the literature, we evaluated the 100 most highly cited DBS publications. An overview of the top 10 cited publications is found in Table 4 and a list of the top 100 in online supplementary Table 4 . The top-cited paper is on DBS for treatmentresistant depression by Mayberg and colleagues [20] from the University of Toronto, with 2,269 citations. Notably, the majority of both the top 10 cited DBS publications and the top 100 are on DBS for Parkinson's disease. The top 100 articles originated from 50 different institutions, with a combined total of 40,967 citations (online suppl. Table 4). Institutions that accounted for the most highly cited reports include the University of Toronto (17 articles and 7,705 citations), Pitié-Salpêtrière/Saint Antoine University Hospital (6 articles, 2,113 citations), Cleveland Clinic/ Case Western Reserve University (4 articles, 1,253), and the University of Amsterdam (4 articles, 1,669 citations). Authors with the most highly cited reports include Lozano AM (22 articles, 9,868 citations), Lang AE (11 articles, 4,851 citations), Benabid AL (9 articles, 3,548 citations), Pollak P ( 9 articles, 3,548 citations), and Agid Y ( 9 articles, 3,402 citations) (online suppl. Table 5).

\section{Active NIH-Funded Projects}

We surveyed a sample of currently funded DBS research from readily available databases currently funded to obtain direct measures of the state and future of DBS research. We first examined active DBS projects funded by the NIH (the USA). The NIH provides an easily accessible database that is representative of ongoing research 
activities, although no such comprehensive database is available for the European continent or Asian countries as a group. Our search of the RePORT database for all active projects on DBS funded by the NIH generated an initial list of 356 entries. Following the removal of duplicates and screening for pertinence to DBS, a total of 172 projects were identified (Fig. 1b). The year active projects commenced ranged from 1999 (1 project, 0.6\%) to 2021 (16 projects, 9.3\%). Based on the 165 (95.9\%) records that provided information on a proposed completion date, the average estimated project duration is $59.1 \pm 2.8$ months (4.9 \pm 0.2 years). Not accounting for $12(7.0 \%)$ projects that omitted information on financial costs, total NIH funding of active projects was estimated at 92.2 million USD. This amounts to an average total project cost of $576,051 \pm 45,957$ USD. Annually, a DBS project has an average cost of $117,040 \pm 9,337$ USD.

Compared to published DBS studies, active projects focused more on psychiatric disorders $(24.3 \%$ active vs. $15.3 \%$ published), epilepsy ( $8.8 \%$ active vs. $5.2 \%$ published), and cognitive disorders (14.6\% active vs. $3.4 \%$ published). Only $46.5 \%$ of active projects pertained to movement disorders compared to $71.6 \%$ of published works. Nevertheless, motor areas (e.g., STN, GPi, and ventral intermediate nucleus of thalamus) still account for a similar percentage of regions targeted in active projects (78.0\%) versus published studies (78.3\%).

In terms of study design, $29.1 \%$ of active projects funded by the NIH were categorized as clinical trials (vs. 10.2\% published). It was also more common for active projects to include a neuroimaging/electrophysiological component (69.8\% active vs. $25.8 \%$ published). Similarly, $37.8 \%$ of active projects focused on developing new stimulation techniques and technologies, compared to $6.5 \%$ of total published DBS works. Thirty (17.4\%) grants focused on increasing the DBS parameter space, and 35 (20.3\%) grants focused on developing adaptive closed-loop systems.

Novel projects that are currently evaluating new indications and brain targets include the use of central thalamic DBS to regulate arousal (project ID: 5R01NS111019-02) and treat traumatic brain injury (project ID: 5UH3NS095554-04). Other studies are targeting the cerebellum to enhance rehabilitation poststroke (project ID: 5R01NS105899-04) and post-traumatic brain injury (project ID: 1R01NS116384-01). Projects focused on advancing DBS technologies are developing closed-loop systems for freezing of gait using neural and kinematic feedback (project ID: 5UH3NS107709-02). Other studies are using Medtronic Activa $^{\mathrm{TM}} \mathrm{PC}+\mathrm{S}$ devices, capable of recording and stimu-

Where Are We with DBS? lating simultaneously, in patients with essential tremor (project ID: 5UH3NS095553-03) and OCD (project ID: 5UH3NS100548-03). Smaller and less invasive electrodes are also being tested using improved electrode materials (ultralow impedance platinum-iridium alloy coatings) to facilitate the development of closed-loop DBS (project ID: 5R44NS103714-02).

\section{Active DFG-Funded Projects}

To achieve a more global perspective of DBS research, we also evaluated DBS research outside the USA. Taking advantage of the ease of access, we searched the GEPRIS database of the German Research Foundation (DFG). Our search of the GEPRIS database generated a list of 65 entries. After removing duplicates and projects without pertinence to DBS, 34 projects were analyzed (Fig. 1c). Active projects were initiated between 2011 (1 project, $2.9 \%)$ and 2021 (6 projects, $17.6 \%)$. In contrast to the $\mathrm{NIH}$, the DFG-linked GEPRIS database does not provide information on funding.

DFG-sponsored active DBS studies focused primarily on movement disorders (26 projects, $76.5 \%$ ), which included Parkinson's disease (16 projects, $47.0 \%$ ), dystonia (2 projects, $5.9 \%$ ), and essential tremor (1 project, $2.9 \%$ ), among others. There was 1 active project on Tourette syndrome, which represents the only psychiatric indication being investigated. Thus, most studies targeted the basal ganglia (14 projects, $41.2 \%$ ), of which 6 targeted the STN. One project examines the mesencephalic locomotor region in rodents as a possible target for Parkinson's disease and other movement disorders (project ID: 424778381).

Most projects were conducted in humans (16 projects, $47.0 \%$ ), while the others involved rodents (10 projects, $29.4 \%$ ), cell cultures (2 projects, $5.9 \%$ ), nonhuman primates (1 project, $2.9 \%$ ), or material science and computational models. Regarding study topics, active projects primarily addressed a neuroimaging/electrophysiological component ( 24 projects, $70.6 \%$ ). Otherwise, projects centered on technological development (6 projects, $17.6 \%)$, while even fewer addressed therapeutic effects, such as experimental studies in movement disorders and oneclinicalstudyinHuntington'sdisease(NCT02535884).

\section{Discussion}

We identified and categorized 8,974 publications on DBS and another $206 \mathrm{NIH}$ - or DFG-sponsored projects that are underway. The number of DBS-related studies has 
grown rapidly since its introduction in the 1950s and after the pivotal report of thalamic DBS as an alternative to thalamotomy in 1987 [12]. DBS shows no signs of slowing given the potential for optimizing therapies for novel indications and implementing adaptive stimulation paradigms.

\section{Current Trends and Future Directions}

Our overview of the DBS literature revealed many interesting trends. With regard to country of origin, the USA has published the most DBS content and will likely continue to do so given their activity in conducting clinical trials [3]. Our analyses of NIH- and DFG-sponsored projects revealed that many active studies focus on developing new stimulation techniques (e.g., expanding DBS parameter space) and technologies (e.g., closed-loop or adaptive stimulation). In addition to the USA, other major contributing countries are Germany, the UK, France, and Canada, where the top publishing authors are from. Nevertheless, advancing DBS research has become a global effort with more than 20,000 contributing authors from 91 countries.

Given that movement disorders are the most common indication for DBS and its regulatory approval occurred around the early 2000s (i.e., essential tremor in 1997, Parkinson's disease in 2002, and dystonia in 2003 [13, 40, 41]), most published works on DBS pertained to this field. However, this is rapidly changing with a shift toward novel indications, including psychiatric and cognitive disorders [4]. Movement disorders account for $71.6 \%$ of published works compared to $62.0 \%$ of registered clinical trials, as reported in an update in 2019 [3] and only $46.5 \%$ of active NIHfunded projects. In contrast, psychiatric disorders account for $15.3 \%$ of publications, $23.7 \%$ of registered clinical trials [3], and $24.3 \%$ of active NIH-funded projects. DBS for cognitive disorders is only recently emerging since it accounts for $3.4 \%$ of publications and $4.7 \%$ of registered clinical trials [3], but $14.6 \%$ of active NIH-funded projects. These trends are not observed in the active DFG studies since movement disorders studies still prevail (76.5\% movement disorders vs. $2.9 \%$ psychiatric and $0 \%$ cognitive indications).

For published works, the distribution of brain targets reflects the same pattern as that of the disorders, given their close association. However, this is not the case for active NIH-funded DBS projects. Despite a decrease in the proportion of movement disorders as indications for new DBS studies, there is no difference in brain regions targeted in active projects versus published studies. This could be due to the repurposing of known targets for novel indications. For example, the STN and GPi have been recognized as candidate structures for treatmentresistant depression [42]. Both structures play a role in basal ganglia functional circuits, including motor, oculomotor, associative, and limbic loops. As such, reports of a decline in depression scores during STN or GPi DBS for Parkinson's disease have been attributed to the inadvertent stimulation of limbic subcircuits $[43,44]$. Similarly, the use of STN DBS for OCD followed observations of obsessive-compulsive symptom relief in DBS patients treated for Parkinson's disease with comorbid OCD [4547].

Our results also highlight the increasing use of neuroimaging and electrophysiological techniques beyond standard clinical practice. The use of imaging/electrophysiology accounts for only $25.8 \%$ of published works compared to $34.7 \%$ of registered clinical trials [3] and $69.8 \%$ and $70.6 \%$ of active NIH- and DFG-sponsored projects, respectively. Even within the published literature, we observed an exponential increase in the use of imaging/electrophysiology, from as low as 0.1 publications per year (1981-1990) to 175.5 (2011-2020). Many factors likely account for this trend, such as increased access and affordability to image patients for research purposes. We also have increased knowledge of safety limits for imaging patients with DBS implants, as demonstrated by recent experience in scanning DBS patients with 1.5or 3-T magnetic resonance imaging [48]. Technical advances in artifact removal and source localization have also made it possible to record DBS patients using magnetoencephalography [49]. The use of imaging/electrophysiology also provides insight into the understanding of the mechanism(s) of DBS, which is required to advance the field. In particular, recording of local field potentials from contacts of the implanted DBS electrodes has not only helped to understand the pathophysiology of movement disorders but has also paved the way for developing adaptive and closed-loop DBS techniques [50, 51]. DBS modulation of abnormal neuronal oscillations in Parkinson's disease has been demonstrated using both local field potentials and magnetoencephalography [52]. Possible effects of DBS on synaptic plasticity and network reorganization are being evaluated with functional magnetic resonance imaging and single-photon emission computed tomography [53]. Other studies used ${ }^{18} \mathrm{~F}$-fluorodopa positron emission tomography to discount the proposed neuroprotective effects of DBS by showing similar dopamine terminal loss as non-DBS-treated Parkinson's patients [54]. Moreover, the use of imaging/electrophysiology allows for the exploration of biomarkers that could be used to optimize therapy by guiding the selection of DBS candidates, targets, and settings in an open- or closedloop fashion $[55,56]$. 
The diversity of active NIH- and DFG-sponsored projects reflects the growing emergence of new stimulation techniques, particularly in increasing the DBS parameter space. Examples of novel stimulation paradigms include the use of alternative waveforms [57], interleaving [58], kilohertz stimulation frequencies [59], and current steering $[60,61]$. Yet, interest prevails in developing adaptive closed-loop systems. Adaptive DBS technology is characterized by simultaneous recording and stimulation of brain structures and can be active intermittently to optimize current delivery. This improves therapeutic outcomes while reducing adverse effects associated with chronic stimulation, such as speech impairment and an increased risk of falls [5-7, 62]. Adaptive DBS systems also have the potential to streamline clinical practice by reducing or eliminating the need for individualized programming and prolonging battery life [63, 64]. This would reduce the need for frequent patient visits and increase the DBS center's catchment area.

\section{Methodological Limitations}

An important limitation of this study is its reliance on only 2 sources - the US-based grants registry, RePORT, and German DFG GEPRIS database - for insight into the future directions of DBS research. Since we assessed active DBS projects solely funded by the NIH or DFG, there may be a bias for developing new stimulation techniques and technologies. Nevertheless, these reporting tools promote public accountability as well as transparency on project duration for researchers and organizations interested in conducting DBS research.

\section{Conclusions}

This overview of DBS-related publications and active NIH- or DFG-funded studies maps the evolution of DBS over more than 40 years. It highlights the worldwide topography, subject matter, and pragmatic factors that characterize this important research. An understanding of past and current trends offers insight into what we can expect in the future regarding better/novel target selection, new indications, improved stimulation paradigms, and advanced DBS technologies. This knowledge can guide decision-making processes for DBS clinicians, researchers, and stakeholders to optimize therapeutic outcomes for patients.

\section{Statement of Ethics}

An ethics statement is not applicable because this study is based exclusively on published literature.

\section{Conflict of Interest Statement}

A.M.L. is a consultant to Abbott, Boston Scientific, Medtronic, and Functional Neuromodulation. J.K.K. is a consultant to Boston Scientific and Medtronic. All other authors declare no conflicts of interest.

\section{Funding Sources}

This work is supported by the Canadian Institutes of Health Research (I.E.H.) and the Canada Research Chair in Neuroscience (A.M.L.). The funding sources had no role in the study design, data collection, data analysis, data interpretation, writing of the report, or decision to submit for publication.

\section{Author Contributions}

I.E.H. and A.M.L. contributed to the study design. I.E.H. contributed to writing and figure preparation and prepared the initial draft of the manuscript and figures; all the authors reviewed and/ or edited the manuscript and approved the submitted version. I.E.H. and F.W.F. performed analyses of data. A.M.L. contributed to study supervision.

\section{Data Availability Statement}

The data that support the findings of this review are openly available in PubMed (https://pubmed.ncbi.nlm.nih.gov/), Web of Science (https://login.webofknowledge.com), NIH RePORT database (https://report.nih.gov/), and DFG GEPRIS database (https:// gepris.dfg.de/gepris).

\section{References}

1 Lozano AM, Eltahawy H. How does DBS work? Suppl Clin Neurophysiol. 2004;57: 733-6.

2 Lozano AM, Lipsman N. Probing and regulating dysfunctional circuits using deep brain stimulation. Neuron. 2013;77(3):406-24.

3 Harmsen IE, Elias GJB, Beyn ME, Boutet A, Pancholi A, Germann J, et al. Clinical trials for deep brain stimulation: current state of affairs. Brain Stimul. 2020;13:378-85.

4 Lozano AM, Lipsman N, Bergman H, Brown P, Chabardes S, Chang JW, et al. Deep brain stimulation: current challenges and future directions. Nat Rev Neurol. 2019;15:148-60.

5 Moreau C, Defebvre L, Destée A, Bleuse S, Clement F, Blatt JL, et al. STN-DBS frequen- cy effects on freezing of gait in advanced Parkinson disease. Neurology. 2008 Jul;71(2): 80-4.

6 Schrader C, Capelle HH, Kinfe TM, Blahak C, Bäzner H, Lütjens $\mathrm{G}$, et al. GPi-DBS may induce a hypokinetic gait disorder with freezing of gait in patients with dystonia. Neurology. 2011 Aug;77(5):483-8. 
7 Xie T, Padmanaban M, Bloom L, MacCracken E, Bertacchi B, Dachman A, et al. Effect of low versus high frequency stimulation on freezing of gait and other axial symptoms in Parkinson patients with bilateral STN DBS: a mini-review. Transl Neurodegener. 2017 May;6:13.

8 Krauss JK, Lipsman N, Aziz T, Boutet A, Brown $\mathrm{P}$, Chang JW, et al. Technology of deep brain stimulation: current state and future directions. Nat Rev Neurol. 2021 Feb;17(2):75-87.

9 Hariz MI, Blomstedt P, Zrinzo L. Deep brain stimulation between 1947 and 1987: the untold story. Neurosurg Focus. 2010 Aug;29(2): E1.

10 Stock G, Sturm V, Schmitt HP, Schlör KH. The influence of chronic deep brain stimulation on excitability and morphology of the stimulated tissue. Acta Neurochir. 1979; 47(1-2):123-9.

11 Brice J, McLellan L. Suppression of intention tremor by contingent deep-brain stimulation. Lancet. 1980;1:1221-2.

12 Benabid AL, Pollak P, Louveau A, Henry S, Rougemont J. Combined (thalamotomy and stimulation) stereotactic surgery of the VIM thalamic nucleus for bilateral Parkinson disease. Appl Neurophysiol. 1987;50:344-6.

13 Koller W, Pahwa R, Busenbark K, Hubble J, Wilkinson S, Lang A, et al. High-frequency unilateral thalamic stimulation in the treatment of essential and parkinsonian tremor. Ann Neurol. 1997 Sep;42(3):292-9.

14 Levy RM, Lamb S, Adams JE. Treatment of chronic pain by deep brain stimulation: long term follow-up and review of the literature. Neurosurgery. 1987 Dec;21(6):885-93.

15 Coubes $\mathrm{P}$, Echenne B, Roubertie A, Vayssière N, Tuffery S, Humbertclaude V, et al. [Treatment of early-onset generalized dystonia by chronic bilateral stimulation of the internal globus pallidus. Apropos of a case]. Neurochirurgie. 1999 May;45(2):139-44. French.

16 Krauss JK, Pohle T, Weber S, Ozdoba C, Burgunder JM. Bilateral stimulation of globus pallidus internus for treatment of cervical dystonia. Lancet. 1999 Sep 4;354(9181):837-8.

17 Kumar R, Dagher A, Hutchison WD, Lang AE, Lozano AM. Globus pallidus deep brain stimulation for generalized dystonia: clinical and PET investigation. Neurology. 1999 Sep 11;53(4):871-4.

18 Vandewalle V, van der Linden C, Groenewegen HJ, Caemaert J. Stereotactic treatment of Gilles de la Tourette syndrome by high frequency stimulation of thalamus. Lancet. 1999 Feb 27;353(9154):724.

19 Nuttin B, Cosyns P, Demeulemeester H, Gybels J, Meyerson B. Electrical stimulation in anterior limbs of internal capsules in patients with obsessive-compulsive disorder. Lancet. 1999 Oct;354(9189):1526.

20 Mayberg HS, Lozano AM, Voon V, McNeely HE, Seminowicz D, Hamani C, et al. Deep brain stimulation for treatment-resistant depression. Neuron. 2005 Mar;45(5):651-60.

21 Laxton AW, Tang-Wai DF, McAndrews MP, Zumsteg D, Wennberg R, Keren R, et al. A phase I trial of deep brain stimulation of memory circuits in Alzheimer's disease. Ann Neurol. 2010 Oct;68(4):521-34.

22 Lipsman N, Woodside DB, Giacobbe P, Hamani C, Carter JC, Norwood SJ, et al. Subcallosal cingulate deep brain stimulation for treatment-refractory anorexia nervosa: a phase $1 \mathrm{pi}-$ lot trial. Lancet. 2013 Apr;381(9875):1361-70.

23 Wilcox RA, Cole MH, Wong D, Coyne T, Silburn P, Kerr G. Pedunculopontine nucleus deep brain stimulation produces sustained improvement in primary progressive freezing of gait. J Neurol Neurosurg Psychiatry. 2011 Nov;82(11):1256-9.

24 Sturm V, Fricke O, Bührle CP, Lenartz D, Maarouf M, Treuer H, et al. DBS in the basolateral amygdala improves symptoms of autism and related self-injurious behavior: a case report and hypothesis on the pathogenesis of the disorder. Front Hum Neurosci. 2013 Jan;6:341.

25 Baldermann JC, Kohl S, Visser-Vandewalle V, Klehr M, Huys D, Kuhn J. Deep brain stimulation of the ventral capsule/ventral striatum reproducibly improves symptoms of body dysmorphic disorder. Brain Stimul. 2016 Nov-Dec;9(6):957-9.

26 Rezai AR, Sederberg PB, Bogner J, Nielson DM, Zhang J, Mysiw WJ, et al. Improved function after deep brain stimulation for chronic, severe traumatic brain injury. Neurosurgery. 2016 Aug;79(2):204-11.

27 Green AL, Nandi D, Armstrong G, Carter H, Aziz T. Post-herpetic trigeminal neuralgia treated with deep brain stimulation. J Clin Neurosci. 2003 Jul;10(4):512-4.

28 Green AL, Debrah E, Roy HA, Rebelo P, Moosavi SH. Letter to the editor: thalamic deep brain stimulation may relieve breathlessness in COPD. Brain Stimul. 2019 May-Jun;12(3):827-8.

29 Fenoy AJ, Schiess MC. Deep brain stimulation of the dentato-rubro-thalamic tract: outcomes of direct targeting for tremor. Neuromodulation. 2017 Jul;20(5):429-36.

30 Martinez V, Hu SC, Foutz TJ, Ko A. Successful treatment of holmes tremor with deep brain stimulation of the prelemniscal radiations. Front Surg. 2018 May;5:21.

31 Lee DJ, Dallapiazza RF, De Vloo P, Elias GJB, Fomenko A, Boutet A, et al. Inferior thalamic peduncle deep brain stimulation for treatment-refractory obsessive-compulsive disorder: a phase 1 pilot trial. Brain Stimul. 2019 Mar-Apr;12(2):344-52.

32 Raymaekers S, Luyten L, Bervoets C, Gabriëls L, Nuttin B. Deep brain stimulation for treatment-resistant major depressive disorder: a comparison of two targets and long-term follow-up. Transl Psychiatry. 2017 Oct;7(10): e1251.

33 Welter ML, Alves Dos Santos JF, Clair AH, Lau B, Diallo HM, Fernandez-Vidal S, et al. Deep brain stimulation of the subthalamic, accumbens, or caudate nuclei for patients with severe obsessive-compulsive disorder: a randomized crossover controlled study. Biol Psychiatry. 2021 Nov 15;90(10):e45-7.
34 Testini P, Zhao CZ, Stead M, Duffy PS, Klassen BT, Lee KH. Centromedian-parafascicular complex deep brain stimulation for tourette syndrome: a retrospective study. Mayo Clin Proc. 2016 Feb;91(2):218-25.

35 Abdallat M, Saryyeva A, Blahak C, Wolf ME, Weigel R, Loher TJ, et al. Centromedian-parafascicular and somatosensory thalamic deep brain stimulation for treatment of chronic neuropathic pain: a contemporary series of 40 patients. Biomedicines. 2021 Jun 25;9(7):731.

36 Chang CH, Chen SY, Hsiao YL, Chen SJ, Tsai ST, Chang $\mathrm{CH}$, et al. Hypomania-like syndrome induced by deep brain stimulation of bilateral anterior limbs of the internal capsules. Prog Neuropsychopharmacol Biol Psychiatry. 2009 Aug;33(5):906-7.

37 Calandra CR, García Fernández C, Raina GB, Docampo J, Barbosa N, Piedimonte F, et al. Intraparenchymal cystic lesion after deep brain stimulation surgery: an unusual complication. Parkinsonism Relat Disord. 2019 Jul;64:354-5.

38 Siso García P, Suárez San Martín E, Saiz Ayala A, Blázquez Estrada M. Idiopathic delayedonset edema associated with deep brain stimulation. Neurologia. 2021 Jan-Feb;36(1):84-6.

39 Themistocleous MS, Boviatsis EJ, Stavrinou LC, Stathis P, Sakas DE. Malignant neuroleptic syndrome following deep brain stimulation surgery: a case report. J Med Case Rep. 2011 Jun;5:255

40 Zhang K, Bhatia S, Oh MY, Cohen D, Angle C, Whiting D. Long-term results of thalamic deep brain stimulation for essential tremor. J Neurosurg. 2010 Jun;112(6):1271-6.

41 Limousin P, Krack P, Pollak P, Benazzouz A, Ardouin C, Hoffmann D, et al. Electrical stimulation of the subthalamic nucleus in advanced Parkinson's disease. N Engl J Med. 1998 Oct;339(16):1105-11.

42 Drobisz D, Damborská A. Deep brain stimulation targets for treating depression. Behav Brain Res. 2019 Feb;359:266-73.

43 Birchall EL, Walker HC, Cutter G, Guthrie S, Joop A, Memon RA, et al. The effect of unilateral subthalamic nucleus deep brain stimulation on depression in Parkinson's disease. Brain Stimul. 2017 May-Jun;10(3): 651-6.

44 Combs HL, Folley BS, Berry DT, Segerstrom SC, Han DY, Anderson-Mooney AJ, et al. Cognition and depression following deep brain stimulation of the subthalamic nucleus and globus pallidus pars internus in Parkinson's disease: a meta-analysis. Neuropsychol Rev. 2015 Dec;25(4):439-54.

45 Mallet L, Mesnage V, Houeto JL, Pelissolo A, Yelnik J, Behar C, et al. Compulsions, Parkinson's disease and stimulation. Lancet. 2002 Oct;360(9342):1302-4.

46 Fontaine D, Mattei V, Borg M, von Langsdorff D, Magnie MN, Chanalet S, et al. Effect of subthalamic nucleus stimulation on obsessive-compulsive disorder in a patient with Parkinson's disease: case report. J Neurosurg. 2004;100(6):1084-6. 
47 Mallet L, Polosan M, Jaafari N, Baup N, Welter $\mathrm{ML}$, Fontaine D, et al. Subthalamic nucleus stimulation in severe obsessive-compulsive disorder. N Engl J Med. 2008 Nov;359(20):2121-34.

48 Boutet A, Rashid T, Hancu I, Elias GJB, Gramer RM, Germann J, et al. Functional MRI safety and artifacts during deep brain stimulation: experience in 102 patients. Radiology. 2019 Oct;293(1):174-83.

49 Harmsen IE, Rowland NC, Wennberg RA, Lozano AM. Characterizing the effects of deep brain stimulation with magnetoencephalography: a review. Brain Stimul. 2018 MayJun;11(3):481-91.

50 He S, Baig F, Mostofi A, Pogosyan A, Debarros J, Green AL, et al. Closed-loop deep brain stimulation for essential tremor based on thalamic local field potentials. Mov Disord. 2021 Apr;36(4):863-73.

51 Sinclair NC, McDermott HJ, Fallon JB, Perera T, Brown P, Bulluss KJ, et al. Deep brain stimulation for Parkinson's disease modulates highfrequency evoked and spontaneous neural activity. Neurobiol Dis. 2019 Oct;130:104522.

52 Oswal A, Beudel M, Zrinzo L, Limousin P, Hariz M, Foltynie T, et al. Deep brain stimulation modulates synchrony within spatially and spectrally distinct resting state networks in Parkinson's disease. Brain. 2016 May; 139(Pt 5):1482-96.
$53 \mathrm{Ko} \mathrm{JH}$, Tang CC, Eidelberg D. Brain stimulation and functional imaging with fMRI and PET. Handb Clin Neurol. 2013;116:77-95.

54 Hilker R, Portman AT, Voges J, Staal MJ, Burghaus L, van Laar T, et al. Disease progression continues in patients with advanced Parkinson's disease and effective subthalamic nucleus stimulation. J Neurol Neurosurg Psychiatry. 2005 Sep;76(9):1217-21.

55 Boutet A, Madhavan R, Elias GJB, Joel SE, Gramer R, Ranjan M, et al. Predicting optimal deep brain stimulation parameters for Parkinson's disease using functional MRI and machine learning. Nat Commun. 2021 May; 12(1):3043.

56 Neumann WJ, Turner RS, Blankertz B, Mitchell T, Kühn AA, Richardson RM. Toward electrophysiology-based intelligent adaptive deep brain stimulation for movement disorders. Neurotherapeutics. 2019 Jan;16(1):105-18.

57 De Jesus S, Okun MS, Foote KD, MartinezRamirez D, Roper JA, Hass CJ, et al. Square biphasic pulse deep brain stimulation for Parkinson's disease: the BiP-PD study. Front Hum Neurosci. 2019 Oct;13:368.

58 França C, Barbosa ER, Iglesio R, Teixeira MJ, Cury RG. Interleaving stimulation in Parkinson disease: interesting to whom? World Neurosurg. 2019 Oct;130:e786-93.
59 Harmsen IE, Lee DJ, Dallapiazza RF, De Vloo $\mathrm{P}$, Chen R, Fasano A, et al. Ultra-high-frequency deep brain stimulation at $10,000 \mathrm{~Hz}$ improves motor function. Mov Disord. 2019 Jan;34(1):146-8.

60 Contarino MF, Bour LJ, Verhagen R, Lourens MA, de Bie RM, van den Munckhof $P$, et al. Directional steering: a novel approach to deep brain stimulation. Neurology. 2014 Sep; 83(13):1163-9.

61 Pollo C, Kaelin-Lang A, Oertel MF, Stieglitz L, Taub E, Fuhr P, et al. Directional deep brain stimulation: an intraoperative double-blind pilot study. Brain. 2014 Jul;137(Pt 7):201526.

62 Rosa M, Arlotti M, Marceglia S, Cogiamanian F, Ardolino G, Fonzo AD, et al. Adaptive deep brain stimulation controls levodopa-induced side effects in Parkinsonian patients. Mov Disord. 2017 Apr;32(4):628-9.

63 Swann NC, de Hemptinne C, Thompson MC, Miocinovic S, Miller AM, Gilron R, et al. Adaptive deep brain stimulation for Parkinson's disease using motor cortex sensing. J Neural Eng. 2018 Aug;15(4):046006.

64 Velisar A, Syrkin-Nikolau J, Blumenfeld Z, Trager MH, Afzal MF, Prabhakar V, et al. Dual threshold neural closed loop deep brain stimulation in Parkinson disease patients. Brain Stimul. 2019 Jul-Aug;12(4):868-76. 